\section{(C) OPEN ACCESS}

\title{
Total workload and recovery in relation to worktime reduction: a randomised controlled intervention study with time-use data
}

\author{
Helena Schiller, ${ }^{1}$ Mats Lekander, ${ }^{1,2}$ Kristiina Rajaleid, ${ }^{1,3}$ Carina Hellgren, ${ }^{2}$ \\ Torbjörn Åkerstedt, ${ }^{1,2}$ Peter Barck-Holst, ${ }_{1}^{2,4,5}$ Göran Kecklund ${ }^{1,6}$
}

\begin{abstract}
- Additional material is published online only. To view please visit the journal online (http://dx.doi.org/10.1136/ oemed-2017-104592).

${ }^{1}$ Stress Research Institute, Stockholm University, Stockholm, Sweden

${ }^{2}$ Department of Clinical Neuroscience, Karolinska Institutet, Stockholm, Sweden ${ }^{3}$ Centre for Health Equity Studies, Stockholm University and Karolinska Institutet, Stockholm, Sweden

${ }^{4}$ Stockholms County Council, Stockholm, Sweden

${ }^{5}$ Centre for Psychiatry Research, Karolinska Institutet, Stockholm, Sweden

${ }^{6}$ Behavioural Science Institute, Radboud University, Nijmegen, The Netherlands
\end{abstract}

\section{Correspondence to}

Helena Schiller, Stress Research Institute, Stockholm University, Stockholm SE-10691, Sweden; helena.schiller@su.se

Received 15 June 2017 Revised 27 October 2017 Accepted 2 November 2017 Published Online First 28 November 2017

\begin{abstract}
Objectives A $25 \%$ reduction of weekly work hours for full-time employees has been shown to improve sleep and alertness and reduce stress during both workdays and days off. The aim of the present study was to investigate how employees use their time during such an intervention: does total workload (paid and non-paid work) decrease, and recovery time increase, when work hours are reduced?
\end{abstract}

Methods Full-time employees within the public sector ( $n=636 ; 75 \%$ women) were randomised into intervention group and control group. The intervention group $(n=370)$ reduced worktime to $75 \%$ with preserved salary during 18 months. Data were collected at baseline, after 9 months and 18 months. Time-use was reported every half-hour daily between 06:00 and 01:00 during 1 week at each data collection. Data were analysed with multilevel mixed modelling.

Results Compared with the control group, the intervention group increased the time spent on domestic work and relaxing hobby activities during workdays when worktime was reduced ( $\mathrm{P} \leq 0.001)$. On days off, more time was spent in free-time activities $(P=0.003)$. Total workload decreased ( $-65 \mathrm{~min}$ ) and time spent in recovery activities increased on workdays (+53 min). The pattern of findings was similar in subgroups defined by gender, family status and job situation.

Conclusions A worktime reduction of $25 \%$ for full-time workers resulted in decreased total workload and an increase of time spent in recovery activities, which is in line with the suggestion that worktime reduction may be beneficial for long-term health and stress.

\section{INTRODUCTION}

High workload together with insufficient time for recovery between workdays might have negative consequences both for the individual and the employer. ${ }^{1}$ Worktime reduction has been proposed to improve work sustainability and support work participation in the labour market, employees' health, work-non-work balance and life satisfaction. According to the effort recovery model, ${ }^{2}$ more time for daily recovery improves work engagement and proactive behaviour at work the next day, ${ }^{3}$ whereas impeded recovery and sustained physiological activation might lead to chronic health impairments. ${ }^{4-7}$ Recovery can be both passive (eg, rest and sleep) and active. ${ }^{2}$ Social activities, creative hobbies and active leisure time activities enable recovery,

\section{Key messages}

What is already known about this subject?

- Worktime reduction is a hot contemporary topic, and it is debated whether its implementation may reduce work stress and improve recovery, to the benefit of long-term health and work performance. Studies of worktime reduction have produced mixed results, and mechanisms behind putative beneficial effects are unclear.

What are the new findings?

- This is the first time that time-use is investigated during a controlled intervention study of worktime reduction, showing that the total workload decreases even though the amount of time spent on domestic tasks increases during workdays. Importantly, the amount of time spent on recovery activities also increases on workdays.

\section{How might this impact on policy or clinical} practice in the foreseeable future?

- The study provides important knowledge for policy makers by showing persistent changes in health behaviours when workload decreases.

mitigating the negative effects of work-related stress on health and sleep. ${ }^{8}$

Experimental studies of a substantial (25\%) reduction of weekly work hours have been indicated to be an effective tool in order to diminish workload and to enhance recovery opportunities. A few controlled intervention studies have shown that worktime reduction from 8 hours/day to 6 hours/day had a positive impact on job exhaustion, sleep quality and mental fatigue. ${ }^{910}$ An earlier paper of the present data material showed that a $25 \%$ reduction of weekly work hours, without a decrease in salary, improved sleep quality and alertness and decreased perceived stress during both workdays and days off. Moreover, sleep duration during workdays increased by approximately 20 min. ${ }^{11}$ In addition, one study on a subsample of these data (social workers working full time) showed that perceived stress levels decreased as a result of the worktime reduction. ${ }^{12}$

It has been suggested that the beneficial effects of worktime reduction might be explained by increased 
time for recovery and social activities. ${ }^{10}$ However, to retrospectively estimate time spent in specific activities in questionnaires may give inaccurate estimates, and an alternative measurement strategy would be to collect time-use data through activity reporting sheets in diaries. The present paper is the first to investigate whether total workload (including both paid and non-paid work) decreases and recovery time increases when work hours are reduced. It is thus hypothesised that the worktime reduction results in diminished total workload and increased time for recovery activities during workdays. However, there may be individual differences in how the additional free time is used. For example, if the extra time is used for non-paid work, total workload and recovery time might be the same as before the intervention. Hence, differences in relation to gender and family situation, for example having children living at home (yes/no), sharing household with a partner (yes/no) and living alone with children (yes/no), were also explored. Time-use patterns were investigated also on days off.

\section{METHODS}

\section{Design and procedure}

Data were collected within a longitudinal controlled intervention study evaluating a $25 \%$ reduction of weekly work hours and its impact on health. ${ }^{13}$ Thirty-three workplaces were included and randomised (see Schiller et $a l^{11}$ for more details). This is thus a cluster-randomised controlled trial. One of the 33 workplaces was not able to recruit new staff and was consequently allocated to the control group, resulting in 17 workplaces in the intervention group and 16 in the control group. Participants in the intervention group preserved their salary, and the workplaces obtained funding for recruiting more staff in order to avoid an increase in workload for the employees. Data were collected at baseline (1-2 months before the intervention; February-May 2005) and approximately 9 months and 18 months after the introduction of reduced work hours (in January/February and October/November 2006). At each data collection participants filled out a questionnaire and completed activity reporting sheets daily during 1 week. Data collections were made at home through the paper-and-pen method.

\section{Study sample}

Initially, 33 workplaces (N) with 919 employees (n) within the public sector agreed to participate, of whom 98 employees dropped out after randomisation. The main reasons for this were changed job/workplace $(n=29)$, parental leave $(n=14)$ and long-term sickness absence $(n=14)$. Altogether 636 employees were included in the study, since they met the inclusion criteria of working full time $(n=180$ were excluded due to part-time work), having reduced the worktime with $25 \%$ according to the employers' time recording data (intervention group) and having participated in the data collection at baseline (see flow chart in online supplementary file). There were 370 individuals in the intervention group and 266 in the control group.

Participants worked at 33 different workplaces (including 3-68 participants per workplace), in four working sectors: social services, $n=170$; technical services, $n=236$; care and welfare, $\mathrm{n}=159$; and call centre, $\mathrm{n}=71$. Almost one-third were shift workers, most of the participants were women, and the average age was $M=44.2$ years, $S D=10.9$ years (range between 20 and 65 years). Half of the participants reported they had children living at home. About $75 \%$ reported they lived with a partner and about 5\% were single parents living alone with children. Background variables are presented in table 1 . In the intervention
Table 1 Descriptive data at baseline presented by group

\begin{tabular}{|c|c|c|c|c|c|c|}
\hline & & \multicolumn{2}{|c|}{ Intervention group } & \multicolumn{2}{|c|}{ Control group } & \multirow{2}{*}{$\begin{array}{l}\begin{array}{l}\text { Group } \\
\text { differences }\end{array} \\
\text { P value }\end{array}$} \\
\hline & & $\mathrm{N}$ & $\%$ & \multirow{2}{*}{$\begin{array}{l}\mathrm{N} \\
266\end{array}$} & \multirow{2}{*}{$\begin{array}{l}\% \\
100\end{array}$} & \\
\hline \multicolumn{2}{|l|}{ Total } & 370 & 100 & & & \\
\hline \multicolumn{2}{|l|}{ Gender } & & & & & 0.157 \\
\hline \multicolumn{2}{|l|}{ Women } & 284 & 77 & 191 & 72 & \\
\hline \multicolumn{2}{|l|}{ Men } & 86 & 23 & 75 & 28 & \\
\hline \multicolumn{2}{|l|}{ Educational level* } & & & & & $0.007 \dagger \ddagger$ \\
\hline \multicolumn{2}{|l|}{ Elementary school } & 35 & 10 & 43 & 16 & \\
\hline \multicolumn{2}{|l|}{$\begin{array}{l}\text { Upper secondary } \\
\text { school }\end{array}$} & 169 & 46 & 131 & 49 & \\
\hline \multicolumn{2}{|l|}{ University courses } & 33 & 9 & 17 & 6 & \\
\hline \multicolumn{2}{|l|}{ University exam } & 132 & 36 & 73 & 27 & \\
\hline \multicolumn{2}{|c|}{$\begin{array}{l}\text { Having children living at } \\
\text { home§ }\end{array}$} & 178 & 48 & 128 & 48 & 0.657 \\
\hline \multicolumn{2}{|c|}{$\begin{array}{l}\text { Sharing household with } \\
\text { another person* }\end{array}$} & 278 & 75 & 198 & 74 & 0.997 \\
\hline \multicolumn{2}{|c|}{$\begin{array}{l}\text { Living alone with } \\
\text { childrenๆ }\end{array}$} & 13 & 4 & 15 & 6 & 0.224 \\
\hline \multicolumn{2}{|l|}{ Working area } & & & & & $0.403^{* *}$ \\
\hline \multicolumn{2}{|l|}{ Social services } & 109 & 30 & 61 & 23 & \\
\hline \multicolumn{2}{|l|}{ Technical services } & 124 & 34 & 112 & 42 & \\
\hline \multicolumn{2}{|l|}{ Care and welfare } & 86 & 23 & 73 & 27 & \\
\hline \multicolumn{2}{|l|}{ Call centre } & 51 & 14 & 20 & 8 & \\
\hline \multirow[t]{3}{*}{ Shift workerst† } & & 89 & 24 & 102 & 38 & $0.000 \dagger$ \\
\hline & \multicolumn{2}{|c|}{$\begin{array}{l}\text { Intervention } \\
\text { group }\end{array}$} & \multicolumn{2}{|c|}{ Control group } & \multicolumn{2}{|c|}{ Group differences } \\
\hline & M & SD & M & SD & $t$ & $P$ value \\
\hline Age (years) & 44.2 & 10.9 & 44.3 & 10.4 & -0.10 & 0.918 \\
\hline $\begin{array}{l}\text { Work } \\
\text { demands (1-4 high } \\
\text { demands) }\end{array}$ & 2.41 & 0.6 & 2.31 & 0.6 & 2.17 & 0.031 \\
\hline $\begin{array}{l}\text { Work control (1-4 } \\
\text { high control) }\end{array}$ & 3.02 & 0.5 & 2.94 & 0.5 & 2.17 & 0.030 \\
\hline \multicolumn{7}{|c|}{$\begin{array}{l}\text { *One missing in intervention group, two missing in control group. } \\
\dagger \chi^{2} \text {-test significant at the } 0.01 \text {-level. } \\
\ddagger \chi^{2} \text {-test University level ( } 1 \text { yes; } 0 \text { no). } \\
\S 49 \text { missing in intervention group, } 27 \text { missing in control group. } \\
\uparrow 49 \text { missing in intervention group, } 29 \text { missing in control group. } \\
{ }^{* *} \chi^{2} \text {-test. } \\
\dagger+O \text { ne missing value in intervention group. }\end{array}$} \\
\hline
\end{tabular}

group, there were 33 individuals who worked 4 days a week and had no reduction of daily work hours at the 9-month follow-up. At the 18-month follow-up, there were 35 such individuals. However, only eight participants worked shorter workweeks at both occasions instead of reducing the daily worktime. They were consequently excluded in a sensitivity analysis.

T-tests showed no age difference or differences in level of job demand or job control between groups (table 1). The number of reported hours of paid work, non-paid work, total workload and recovery activities on workdays or on days off did not differ between groups at baseline $(\mathrm{P}=0.133-0.764)$, except for recovery on days off $(t=2.94 ; \mathrm{P}=0.003)$. The intervention group reported somewhat more time in recovery activities on days off as compared with the control group at baseline. Moreover, $\chi^{2}$ tests indicated differences between groups in two of the background variables presented in table 1: educational level (university level; yes/no) and working shift (yes/no), which were consequently added as covariates in the statistical models. 
ACTIVITY

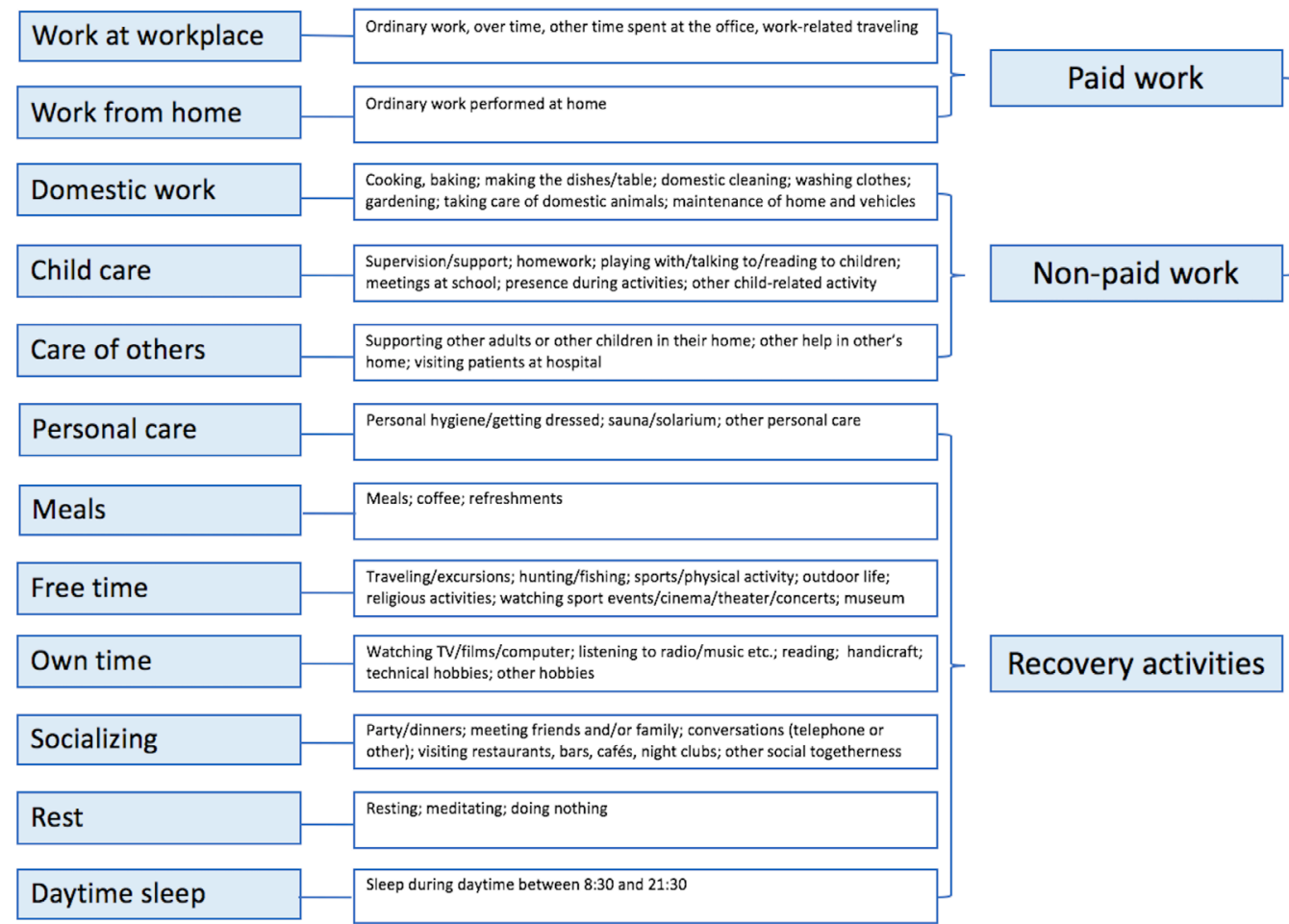

\section{Total workload}

Figure 1 Activity reporting sheet.

\section{Measurements and outcomes}

The questionnaire data included questions on demographic data and work situation, including questions of work environment exposure evaluated through job demands (1, low demands -4 , high demands) and job control (1, low control-4, high control) ${ }^{14}$

Time-use recordings were adapted by a methodology developed at Statistics Sweden, ${ }^{15}$ where the activity reporting sheets include $10 \mathrm{~min}$ intervals and participants should freely register activities during 1 weekday and 1 day during the weekend. The activities are then coded into 99 different types of activities. They are further classified into 24 categories, which in turn are divided into five main groups of activities: paid work, domestic work, studies, personal needs and free time.

Because of the high burden during the data collections in this present study, the activity reporting sheets developed here were divided into intervals of $30 \mathrm{~min}$, from 06:00 to 01:00 the next night, every day during 1 week per measurement period. There were 13 predefined activities that the participants could register: work, work performed at home, household work, care of own children, care of others, personal care, meals, sleep, rest, leisure time, social activities, own time and other. Sleep reported between 08:30 and 21:30 was labelled daytime sleep. The activity 'other' was not used in this study. This resulted in 12 categories, which are defined and presented in figure 1 .

These predefined activities were then divided into four different groups based on the type of activity: (1) paid work (including labour work at the office or at home), (2) non-paid work (including household work, care of own children and care of others), (3) total workload (the sum of paid and non-paid work), and (4) recovery activities (including personal care, meals, rest, leisure time, social activities, own time and daytime sleep). This division is based on the following arguments: first, we wanted to sort out activities that were not related to work (eg, recovery activities vs total workload). Second, we wanted to separate activities outside paid work that might enhance recovery (recovery activities) and activities that might hinder recovery opportunities (non-paid work). All groups of activities were mapped out (see figure 1) and calculated in terms of average number of hours per day on workdays and days off separately. Days of sickness absence were consequently not included in the data analyses. Every measurement week included 7 (days) $\times 39$ (half-hours) $\times 636 \quad$ (individuals) $=173628$ data points. Data were coded as missing if the rate of missing activities for 1 day exceeded 25\% (more than 10 missing activities out of 39). The average rate of internal missing at baseline was $5.4 \%$ (3.0\% among completers and $30.6 \%$ among those who later on dropped off). At the 9 -month follow-up, it was $3.0 \%$ and at the 18-month follow-up $2.9 \%$.

\section{Statistical analyses}

Mean values for workdays and days off for the different categories of the time-use data were studied with multilevel modelling. A value of the intraclass correlation (ICC) of workplace was calculated for each variable at baseline. Although the values of ICC were low (ranging from 0.000 to 0.130 for the activities on workdays and from 0.000 to 0.023 on days off), they were taken into consideration in all statistical analyses, which were based on multilevel mixed models including random effects for workplace at level 2.

The model included the outcome variable and the fixed effects of the between-group factor group (intervention vs control; level 2), the within-group factor time (baseline, 9 months and 18 months; level 1), and the interaction between group and time. The models were fitted by modelling the autocorrelation and adjusted by educational level and working shift (yes/no), since 
the groups differed in these parameters at baseline. The autocorrelation residuals (as indicated by $\mathrm{r}$ ) ranged from -0.238 to 0.228 for the activities on workdays and from -0.011 to 0.245 on days off. Contrast coefficients were calculated by group in order to evaluate the effects by time period (baseline vs 9-month follow-up and 9-month vs 18-month follow-up).

Sensitivity analyses (eg, excluding the eight participants who had 1 day off per week instead of having shorter workdays) were made since those two types of worktime reduction influence time-use patterns differently. Moreover, sensitivity analyses, by excluding the workplace that was not randomised, were made in order to rule out possible bias due to the randomisation procedure.

The subgroup analysis of gender was made by adding a second between-group factor (gender) into the model, resulting in several two-way interactions and one three-way interaction of group $\times$ time $\times$ gender. Additional subgroup analyses of having children living at home (yes/no), living with a partner (yes/no), living alone with children (yes/no), working area (social services/technical services/care and welfare/call centre) and working shift (yes/no) were also performed. Shift workers were defined as employees reporting normal work hours during evening and/or night in the questionnaire at all three measurement periods.

To reduce the risk for type 1 errors, an alpha level of 0.01 was used when testing for statistical significance. Descriptive statistics, t-tests and $\chi^{2}$ tests were computed on SPSS V.24, whereas multilevel analyses and calculation of ICCs were made on Stata V.14.

\section{RESULTS}

\section{Effects on workdays and days off}

There was an effect of the intervention on time-use patterns during workdays. Looking at the 12 predefined categories, the intervention group increased the amount of time spent on own-time activities and domestic work after the introduction of reduced worktime, as compared with the control group. Altogether, there was an effect of the intervention on total workload, which decreased on workdays, and recovery activities, which increased. Data and results are presented in table 2. The adjusted model, including educational level and working shift as covariates, displayed similar results (not reported).

On days off, more time was spent on free-time activities for the intervention group over time as compared with the control group (see data and results in table 2). In the adjusted model, the effect on free-time activities was no longer significant (coefficient $=0.257 ; \mathrm{P}=0.014$; CI 0.051 to 0.464 ).

Sensitivity analyses, where the eight individuals having shorter workweeks instead of shorter workdays were excluded, showed similar results as compared with the original analyses. The same was true for the second sensitivity analysis, where the workplace (with $n=17$ employees) that could not be part of the randomisation was excluded (results not reported).

\section{Exploring subgroups}

When adding gender as an additional between-group factor, the analyses showed no significant effects of gender in relation to the intervention, neither in the crude models (data and results in table 3) nor in the adjusted models. There was no effect of gender on the amount of paid work, non-paid work, total workload or recovery activities, neither on workdays nor on days off (data and results in table 3). The adjusted models did not change these results.
Adding having children living at home (yes/no) as a betweengroup factor showed no differences in the effect of the intervention on time-use depending on being a parent or not (see online supplementary table A). Moreover, adding sharing household with a partner (yes/no) to the model yielded one significant effect on the amount of paid work on days off (see online supplementary table B). This effect disappeared in the adjusted model.

Living alone with children did not influence the effects of the intervention neither in the crude (see online supplementary table C) nor in the adjusted model, and neither did job nature, in terms of working area or working shift (see online supplementary table $\mathrm{D}$ and $\mathrm{E})$.

\section{DISCUSSION}

The aim of this study was to investigate time-use in response to $25 \%$ reduced worktime, which was previously shown to entail beneficial effects on sleep, sleepiness and perceived stress. ${ }^{11}$ During workdays, the total workload decreased with more than 1 hour in response to the intervention. In addition, the total amount of recovery activities increased over time with $53 \mathrm{~min}$ in the intervention group. No similar effects were seen in the control group. The increased recovery activities were own-time activities such as watching TV, being active on the computer or in other hobby activities, reading or listening to the radio. Moreover, the total amount of non-paid work increased over time in the intervention group as compared with the control group, explained by the increasing amount of time spent on domestic work. On days off there was an effect of the reduced work hours on the amount of time spent on free-time activities such as travelling, physical activities and cultural activities, which increased in the intervention group, but not in the control group.

The effects of the intervention could be seen between baseline and the 9-month follow-up, but there were no effects shown between 9 months and 18 months. This strengthens the notion that changes in time-use pattern are actually due to the reduced amount of worktime.

Even though the time spent on domestic work increased on workdays, the total workload diminished. Drawing on the effort recovery model, ${ }^{2}$ the decreasing workload in combination with increasing recovery opportunities could be one of the underlying mechanisms behind the beneficial effects of worktime reduction that was previously shown on sleep, sleepiness and stress. ${ }^{11}$

\section{Exploring the importance of gender, children and job nature}

The time-use patterns in relation to the intervention were similar for men and women as well as for those having children living at home and those who did not. Living with a partner and living alone with children did not influence time-use patterns in relation to the intervention.

Despite the fact that there were no differences between subgroups related to the intervention, it has previously been shown that reduced worktime is associated with less conflict between work and family life, and that the effects of a shorter workday on work family conflict were more appreciated by employees with children as compared with those without children. ${ }^{16}$ In Anttila et al's study, ${ }^{16}$ there were only women participating, ruling out the possibility to investigate gender differences. In the study by Åkerstedt $e t a l^{10}$ on worktime reduction, the strongest effect of the intervention was the increasing time spent with family and friends, which was estimated by the participants to be 'too little' at the start and somewhere between 
Table 2 Data on reported activities on workdays and days off (a mean value expressed in hours and minutes) at the three measurement points and results from the multilevel mixed model in terms of the interactions between group and time

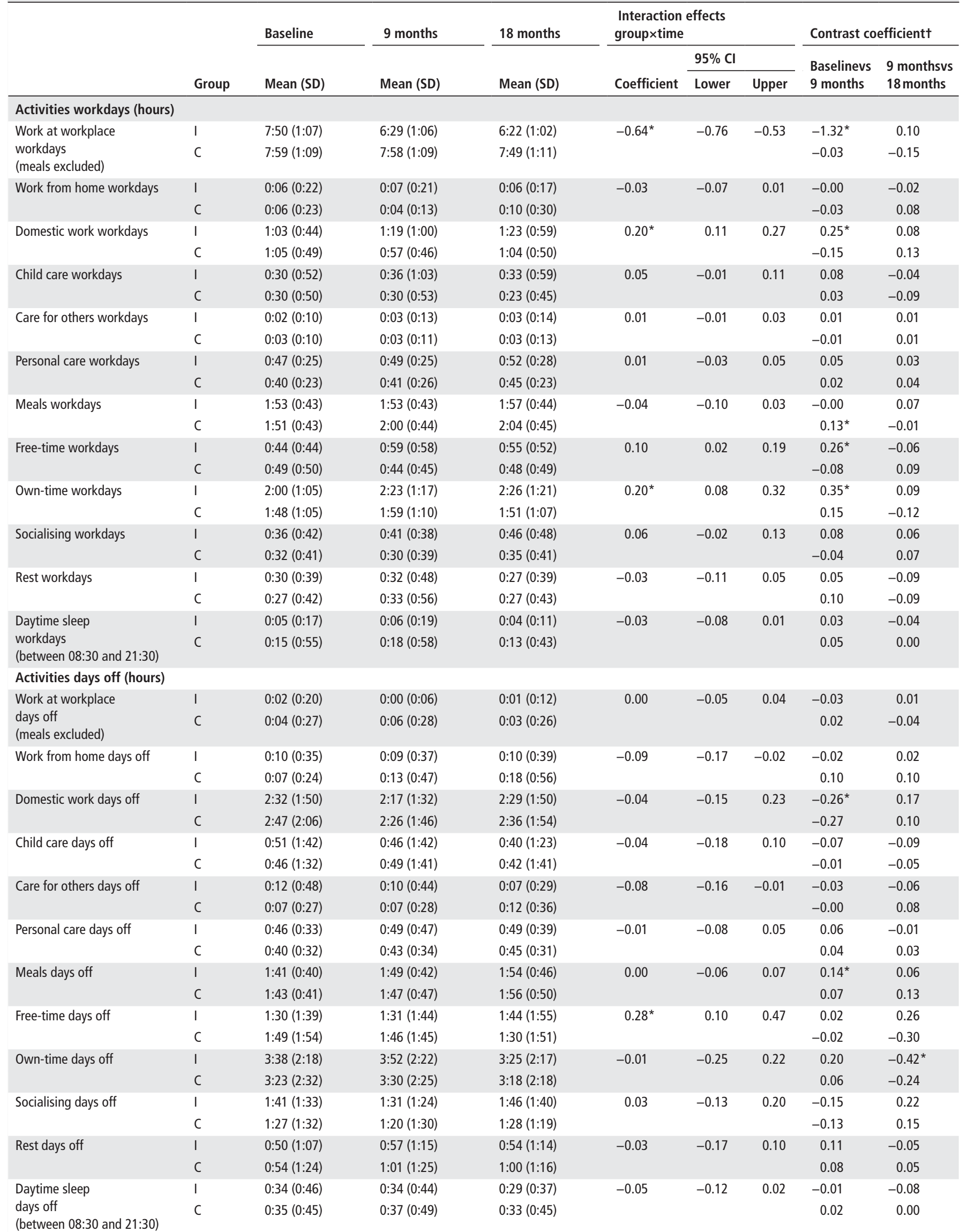




\begin{tabular}{|c|c|c|c|c|c|c|c|c|c|}
\hline & \multirow[b]{3}{*}{ Group } & \multirow{3}{*}{$\begin{array}{l}\text { Baseline } \\
\text { Mean (SD) }\end{array}$} & \multirow{3}{*}{$\begin{array}{l}9 \text { months } \\
\text { Mean (SD) }\end{array}$} & \multirow{3}{*}{$\begin{array}{l}18 \text { months } \\
\text { Mean (SD) }\end{array}$} & \multicolumn{3}{|c|}{$\begin{array}{l}\text { Interaction effects } \\
\text { group xtime }\end{array}$} & \multicolumn{2}{|c|}{ Contrast coefficient $\dagger$} \\
\hline & & & & & & $95 \% \mathrm{Cl}$ & & \multirow{2}{*}{$\begin{array}{l}\text { Baselinevs } \\
9 \text { months }\end{array}$} & \multirow{2}{*}{$\begin{array}{l}9 \text { monthsvs } \\
18 \text { months }\end{array}$} \\
\hline & & & & & Coefficient & Lower & Upper & & \\
\hline \multicolumn{10}{|l|}{ Groups of activities (hours) } \\
\hline \multirow[t]{2}{*}{ Paid work workdays } & I & 7:57 (1:10) & $6: 36(1: 08)$ & $6: 28(1: 04)$ & $-0.67^{*}$ & -0.79 & -0.56 & $-1.32^{*}$ & -0.12 \\
\hline & C & $8: 06(1: 10)$ & $8: 03(1: 10)$ & $7: 59(1: 17)$ & & & & -0.06 & -0.08 \\
\hline \multirow[t]{2}{*}{ Non-paid work workdays } & 1 & $1: 37(1: 07)$ & $1: 59(1: 26)$ & $2: 00(1: 26)$ & $0.25^{*}$ & 0.15 & 0.35 & $-0.34^{*}$ & 0.04 \\
\hline & C & $1: 39(1: 15)$ & $1: 31(1: 17)$ & $1: 31(1: 14)$ & & & & -0.14 & 0.05 \\
\hline \multirow[t]{2}{*}{ Total workload workdays } & I & $9: 34(1: 25)$ & $8: 35(1: 38)$ & $8: 29(1: 44)$ & $-0.42^{*}$ & -0.55 & -0.29 & $-0.98^{*}$ & -0.08 \\
\hline & C & $9: 46(1: 30)$ & $9: 34(1: 31)$ & $9: 31(1: 29)$ & & & & -0.21 & -0.03 \\
\hline \multirow[t]{2}{*}{ Recovery activities workdays } & 1 & $6: 37(1: 28)$ & $7: 26(1: 35)$ & $7: 30(1: 41)$ & $0.28^{*}$ & 0.14 & 0.41 & $0.78^{*}$ & 0.06 \\
\hline & C & $6: 25(1: 40)$ & $6: 47(1: 38)$ & $6: 44(1: 37)$ & & & & $0.33^{*}$ & -0.01 \\
\hline \multirow[t]{2}{*}{ Paid work days off } & I & $0: 13(0: 40)$ & $0: 10(0: 38)$ & $0: 12(0: 40)$ & -0.10 & -0.18 & -0.01 & -0.05 & 0.03 \\
\hline & C & $0: 11(0: 38)$ & $0: 38(0: 19)$ & $0: 22(1: 03)$ & & & & 0.11 & 0.07 \\
\hline \multirow[t]{2}{*}{ Non-paid work days off } & 1 & $3: 35(2: 27)$ & $2: 27(3: 14)$ & $3: 16(2: 21)$ & 0.10 & -0.33 & 0.13 & $-0.37^{*}$ & 0.02 \\
\hline & C & $3: 40(2: 32)$ & $2: 32(3: 22)$ & $3: 29(2: 31)$ & & & & -0.26 & 0.11 \\
\hline \multirow[t]{2}{*}{ Total workload days off } & I & $3: 48(2: 29)$ & $2: 29(3: 25)$ & $3: 28(2: 23)$ & -0.20 & -0.43 & 0.03 & $-0.42^{*}$ & 0.06 \\
\hline & C & 3:52 (2:33) & $2: 33(3: 42)$ & $3: 51(2: 30)$ & & & & -0.15 & 0.19 \\
\hline \multirow[t]{2}{*}{ Recovery activities days off } & I & $10: 40(2: 31)$ & $10: 52(2: 53)$ & $10: 53(2: 43)$ & 0.10 & -0.40 & 0.20 & 0.21 & 0.01 \\
\hline & C & 9:57 (3:33) & $10: 28(3: 07)$ & $10: 27(2: 46)$ & & & & 0.48 & -0.06 \\
\hline
\end{tabular}

* Significant at the 0.01 level.

tContrast coefficients calculated by group and time period.

C, control group; I, intervention group.

'almost' and 'completely sufficient' after the introduction of the reduced worktime.

Statistics Sweden showed in their report Women and men in Sweden ${ }^{17}$ that both men and women (aged between 20 and 64 years) have an average total workload of about 8 hours per day (workdays and days off included). During workdays women spend about 9 hours and men about 9.5 hours in paid and non-paid work. Importantly, more men than women work full time $55 \%$ of all working women and $73 \%$ of all working men in Sweden are full-time workers), and even though women spend more time in non-paid work as compared with men these differences have been more equalised during the past years. The amount of time spent on personal needs and in free-time activities over the week is very similar for men and women in this report, although women spend more time during workdays and men more time on weekends in these activities.

Subgroup analyses of gender were also carried out in the study on worktime reduction and the impact on stress and sleep. ${ }^{11}$ No gender differences were observed in relation to the beneficial effects of the intervention. This could be explained by the fact that changes in time-use patterns were similar for men and women during the intervention, as shown in this present study. Moreover, in Schiller et al's study ${ }^{11}$ no differences were found between those having children living at home and those who did not, in relation to the effects of the intervention, except for parents who experienced lower stress-levels on workdays as a result of the reduced worktime. Thus, the fact of getting more time at home and getting more time for domestic duties (that might imply a higher load when having children in the household) might be beneficial for sleep and stress levels, despite the fact that it implies a higher load of non-paid work. According to Demerouti et al, ${ }^{18}$ the detrimental effects of household work and child care have not been empirically proven, although activities that are obligatory might have a negative effect on recovery. It could be that household work impedes recovery, whereas child care may be a combination of chores and social interaction, and the latter may actually enable recovery and buffer the effects of stress. Another explanation could be that individuals experience the nature of these activities differently. ${ }^{19}$

There are four different job sectors included in this study and $30 \%$ of all participants were shift workers. However, the analyses showed no differences in the effects of reduced worktime depending on job nature.

\section{Strengths and limitations}

This is the first time that time-use is investigated through diary data in relation to an intervention of worktime reduction. Data collection through intensive diary measures enables investigation of time-use patterns in a very detailed manner. The time span of 18 months could be considered long. Measurement periods each lasted during 7 days, resulting in a large amount of data points. The sample is large and the internal missing rate is low, even though it gets larger over time.

Notably, there are some limitations of this study that should be brought forward. This way of collecting time-use data is extensively used in time-use surveys in many countries and is considered to represent valid data. ${ }^{20}$ In this present study though, there were some deviations; participants got the instruction to enter the activity that had taken the largest share of their past $30 \mathrm{~min}$. Thus, we do not know if they were active in two or three categories during the assigned $30 \mathrm{~min}$, and even though participants were instructed to fill out the time-use diary throughout the day we cannot be certain that to what extent this instruction was followed. Importantly, there is no specific time-use activity only referring to physical activity-an activity that has positive effects on excessive fatigue ${ }^{8}$ and well-being. ${ }^{19} 2122$ Thus, it was not possible to investigate this specific type of activity separately. Moreover, we cannot distinguish between active and passive recovery, which is one aspect to consider in the effort recovery 
Table 3 Data on reported activities on workdays and days off (mean value expressed in hours and minutes) for men and women at the three measurement points, respectively, and results from the multilevel mixed model in terms of the interactions between group, time and gender

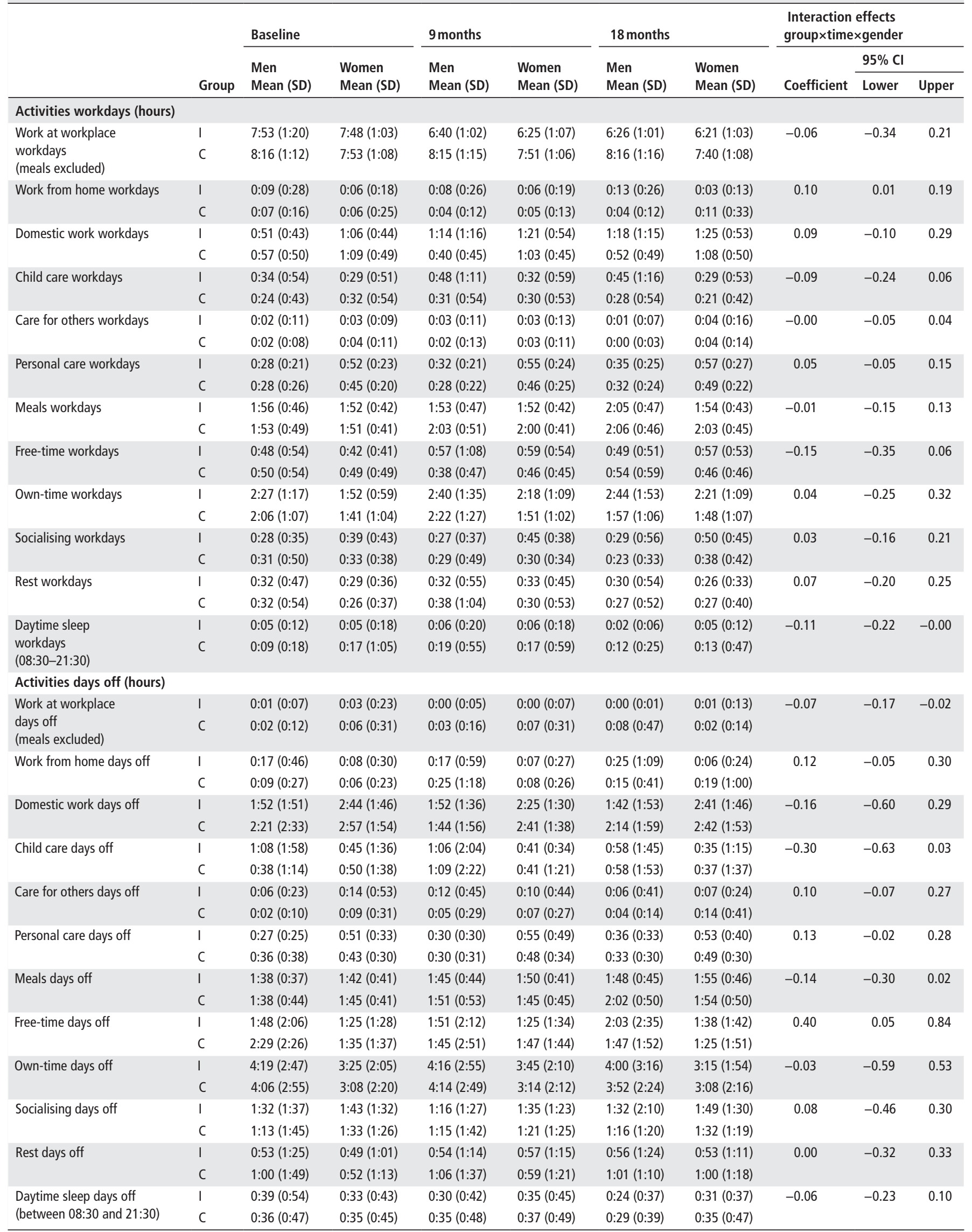




\begin{tabular}{|c|c|c|c|c|c|c|c|c|c|c|}
\hline & \multirow[b]{3}{*}{ Group } & \multicolumn{2}{|l|}{ Baseline } & \multicolumn{2}{|l|}{9 months } & \multicolumn{2}{|l|}{18 months } & \multicolumn{3}{|c|}{$\begin{array}{l}\text { Interaction effects } \\
\text { group } \times \text { timexgender }\end{array}$} \\
\hline & & \multirow{2}{*}{$\begin{array}{l}\text { Men } \\
\text { Mean (SD) }\end{array}$} & \multirow{2}{*}{$\begin{array}{l}\text { Women } \\
\text { Mean (SD) }\end{array}$} & \multirow{2}{*}{$\begin{array}{l}\text { Men } \\
\text { Mean (SD) }\end{array}$} & \multirow{2}{*}{$\begin{array}{l}\text { Women } \\
\text { Mean (SD) }\end{array}$} & \multirow{2}{*}{$\begin{array}{l}\text { Men } \\
\text { Mean (SD) }\end{array}$} & \multirow{2}{*}{$\begin{array}{l}\text { Women } \\
\text { Mean (SD) }\end{array}$} & \multirow[b]{2}{*}{ Coefficient } & \multicolumn{2}{|l|}{$95 \% \mathrm{Cl}$} \\
\hline & & & & & & & & & Lower & Upper \\
\hline \multicolumn{11}{|c|}{ Groups of activities (hours) } \\
\hline \multirow[t]{2}{*}{ Paid work workdays } & 1 & $8: 03(1: 24)$ & $7: 55(1: 05)$ & $6: 49(1: 07)$ & $6: 32(1: 08)$ & $6: 39(1: 03)$ & $6: 25(1: 04)$ & 0.03 & -0.24 & 0.30 \\
\hline & C & $8: 24(1: 12)$ & $8: 00(1: 08)$ & $8: 19(1: 12)$ & 7:57 (1:09) & $8: 21(1: 17)$ & $7: 52(1: 16)$ & & & \\
\hline \multirow[t]{2}{*}{ Non-paid work workdays } & 1 & $1: 29(1: 07)$ & $1: 39(1: 07)$ & $2: 06(1: 41)$ & $1: 56(1: 20)$ & $2: 04(1: 40)$ & $1: 59(1: 21)$ & 0.00 & -0.24 & 0.24 \\
\hline & C & $1: 24(1: 16)$ & $1: 45(1: 15)$ & $1: 15(1: 24)$ & $1: 36(1: 14)$ & $1: 22(1: 19)$ & $1: 34(1: 13)$ & & & \\
\hline \multirow[t]{2}{*}{ Total workload workdays } & 1 & $9: 32(1: 37)$ & $9: 35(1: 21)$ & $8: 56(1: 59)$ & $8: 29(1: 29)$ & $8: 44(2: 03)$ & $8: 25(1: 37)$ & 0.04 & -0.27 & 0.34 \\
\hline & C & $9: 49(1: 38)$ & $9: 45(1: 27)$ & $9: 34(1: 47)$ & $9: 34(1: 24)$ & 9:43 (1:37) & $9: 27(1: 26)$ & & & \\
\hline \multirow[t]{2}{*}{ Recovery workdays } & 1 & $6: 47(1: 44)$ & $6: 34(1: 23)$ & $7: 10(1: 49)$ & $7: 31(1: 30)$ & $7: 18(1: 52)$ & $7: 33(1: 37)$ & -0.05 & -0.37 & 0.27 \\
\hline & C & $6: 33(1: 45)$ & $6: 23(1: 39)$ & $7: 00(1: 44)$ & $6: 43(1: 35)$ & $6: 35(1: 27)$ & $6: 47(1: 40)$ & & & \\
\hline \multirow[t]{2}{*}{ Paid work days off } & 1 & $0: 18(0: 46)$ & $0: 11(0: 38)$ & $0: 18(1: 02)$ & $0: 08(0: 28)$ & $0: 25(1: 09)$ & $0: 08(0: 27)$ & 0.05 & -0.15 & 0.25 \\
\hline & C & $0: 12(0: 29)$ & $0: 12(0: 42)$ & $0: 28(1: 19)$ & $0: 16(0: 40)$ & $0: 24(1: 01)$ & $0: 21(1: 03)$ & & & \\
\hline \multirow[t]{2}{*}{ Non-paid work days off } & 1 & $3: 07(2: 35)$ & $3: 43(2: 23)$ & $3: 10(2: 45)$ & $3: 15(2: 09)$ & $2: 48(2: 29)$ & $3: 24(2: 18)$ & -0.39 & -0.94 & 0.16 \\
\hline & C & $2: 59(2: 52)$ & $3: 55(2: 22)$ & $2: 59(3: 07)$ & $3: 31(2: 11)$ & $3: 14(2: 42)$ & $3: 33(2: 28)$ & & & \\
\hline \multirow[t]{2}{*}{ Total workload days off } & 1 & $3: 26(2: 41)$ & $3: 55(2: 25)$ & $3: 28(2: 45)$ & $3: 24(2: 12)$ & $3: 13(2: 44)$ & $3: 32(2: 16)$ & -0.33 & -0.88 & 0.21 \\
\hline & C & $3: 12(2: 55)$ & 4:07 (2:23) & $3: 28(3: 08)$ & $3: 47(2: 16)$ & $3: 38(2: 40)$ & $3: 55(2: 27)$ & & & \\
\hline \multirow[t]{2}{*}{ Recovery days off } & 1 & $11: 20(2: 37)$ & $10: 28(2: 27)$ & $10: 43(3: 27)$ & $10: 55(2: 42)$ & $10: 55(3: 34)$ & $10: 52(2: 26)$ & -0.20 & -0.90 & 0.51 \\
\hline & C & $10: 38(4: 19)$ & $9: 42(3: 11)$ & $10: 59(3: 25)$ & $10: 17(3: 00)$ & $10: 48(2: 59)$ & $10: 21(2: 42)$ & & & \\
\hline
\end{tabular}

C, control group; I, intervention group.

model. ${ }^{2}$ Concerning the time-use data, it is important to think about the personal meaning of an activity and reconsider the fact that a certain activity might be experienced as recovery for one individual, whereas for another this specific activity might add up to the total workload.

Finally, we do not know if the disadvantage of a reduced salary would somehow have an impact on the time-use pattern (eg, some of the free-time activities might imply high costs) and if this would rule out the positive effects of a worktime reduction. Our findings can only be generalised to situations where worktime is reduced and where salary is retained. Interestingly, Anttila $e{ } l^{16}$ found that the salary reduction following a worktime reduction was considered less important than getting the opportunity to spend more time with one's children and being relieved from workload.

\section{Practical implications and future research}

Our findings extend the knowledge about time-use when worktime is reduced in a society where the working population sometimes finds it hard to create a satisfying balance between work and other domains in life. ${ }^{23}$ Getting more time for domestic duties, such as taking care of children or housework, might make it easier to detach from obligations and relax. It might also release more time for recovery activities during days off. The fact of getting 53 min extra recovery time per workday and more than 1 hour reduced total workload might be beneficial for work-life balance, and it could also have positive effects on health, job performance and life satisfaction..$^{4-7}$ Moreover, there is multifaceted evidence showing that more time for recovery activities is beneficial for sleep and stress. This has been shown in studies drawing on the effort recovery mode $l^{67}$ and in studies investigating interventions of worktime reduction. ${ }^{10-12} 16$

Impeded psychological detachment is related to sleep problems and poor recovery possibilities. ${ }^{24}$ Getting the opportunity to detach from work and being freed from rumination and worry is thus an important part and might facilitate recovery. Notably, in the previous study on the beneficial effects of worktime reduction, ${ }^{11}$ employees felt less stress and worries at bedtime. This indicates that worktime reduction might result in ameliorated recovery opportunities, which in turn might have a positive impact on sleep and well-being. This knowledge is valuable for employees, employers and for policy makers in the debated topic of reduced worktime in exposed sectors.

Future research on worktime reduction should include time-use data in order to further investigate this area and add more valuable knowledge to our findings. These studies should preferably specify internet use, use of social media and physical activity, and participants should preferably indicate if they consider the activity as being a recovery activity or not. Diary data could also be supplemented by the use of apps in smartphones and wearable cameras in order to include objective measures of time-use.

\section{CONCLUSION}

We conclude that during a worktime reduction, the total workload of both paid and non-paid work is reduced. The extra free time during a workweek is used for domestic tasks, but also for recovery activities. The fact that total workload diminishes and recovery activities increase might be one of the underlying mechanisms behind the beneficial effects of a worktime reduction on sleep, sleepiness, stress and bedtime worries that have previously been shown in relation to a $25 \%$ worktime reduction for full-time workers. ${ }^{11}$

Correction notice This article has been corrected since it first published online. Formatting errors in references 12,13 and 16 have been corrected.

Acknowledgements The data of this study were collected within an intervention study carried out in 2005-2006 by the Swedish National Working Life Institute. We would like to thank the former National Working Life Institute for project managing and funding. We also want to express our gratitude to Anna Falkenberg, who was the project leader, and to all the participants — both employees and employers who provided the project with all the valuable data.

Contributors The basic concept and the study design were framed by $\mathrm{CH}$ and TÅ. GK, ML, KR and HS conceptualised the paper. Data collection was administered by PB-H and supervised by CH in 2005-2006. HS drafted the manuscript and 
was responsible for data analyses, supported with feedback from KR on choice of statistical methods and output. All authors were involved in the interpretation of data and have critically revised the manuscript and approved the final version.

Funding The work presented here was supported by funding from the Ministry of Enterprise and Innovation (N2004/8019/ARM) and Stockholm Stress Center-a centre of excellence for research on work-related stress and health. The study is also carried out within the framework of the WOW project, which is funded by the research programme 'Nordforsk, Nordic Program on Health and Welfare'.

Competing interests None declared.

Ethics approval The study was approved by the Stockholm regional ethical review board (reference number: 04-1059/5) and all participants gave their written consent.

Provenance and peer review Not commissioned; externally peer reviewed.

Open Access This is an Open Access article distributed in accordance with the Creative Commons Attribution Non Commercial (CC BY-NC 4.0) license, which permits others to distribute, remix, adapt, build upon this work non-commercially, and license their derivative works on different terms, provided the original work is properly cited and the use is non-commercial. See: http://creativecommons.org/ licenses/by-nc/4.0/

(c) Article author(s) (or their employer(s) unless otherwise stated in the text of the article) 2018. All rights reserved. No commercial use is permitted unless otherwise expressly granted.

\section{REFERENCES}

1 Gjerdingen D, McGovern P, Bekker M, et al. Women's work roles and their impact on health, well-being, and career: comparisons between the United States, Sweden, and The Netherlands. Women Health 2000;31:1-20.

2 Meijman TF, Mulder G. Psychological aspects of workload. In: Drenth PJD, Thierry $\mathrm{H}$, eds. Handbook of work and organizational psychology. Vol. 2: Work psychology. Hove, England: Psychology, 1998:5-33.

3 Sonnentag S. Recovery, work engagement, and proactive behavior: a new look at the interface between nonwork and work. J Appl Psychol 2003;88:518-28.

4 Geurts SA, Sonnentag S. Recovery as an explanatory mechanism in the relation between acute stress reactions and chronic health impairment. Scand J Work Environ Health 2006;32:482-92.

5 Sluiter JK, Frings-Dresen MH, van der Beek AJ, et al. The relation between workinduced neuroendocrine reactivity and recovery, subjective need for recovery, and health status. J Psychosom Res 2001;50:29-37.

6 Sonnentag S, Zijlstra FR. Job characteristics and off-job activities as predictors of need for recovery, well-being, and fatigue. J App/ Psychol 2006;91:330-50.
7 Sonnentag S, Fritz C. Endocrinological processes associated with job stress: catecholamine and cortisol responses to acute and chronic stressors. In: Perrewé PL, Ganster DC, eds. Research in organizational stress and well-being: employee health, coping, and methodologies, 2006:1-59.

8 Winwood PC, Bakker AB, Winefield AH. An investigation of the role of nonwork-time behavior in buffering the effects of work strain. J Occup Environ Med 2007;49:862-71.

9 Nätti J, Anttila T. Experiments of reduced working hours in finnish municipalities. Journal of Human Resource Costing \& Accounting 1999;4:45-61.

10 Åkerstedt T, Olsson B, Ingre M, et al. A 6-hour working day-effects on health and wellbeing. J Hum Ergol 2001;30:197-202.

11 Schiller H, Lekander M, Rajaleid K, et al. The impact of reduced worktime on sleep and perceived stress - a group randomized intervention study using diary data. Scand J Work Environ Health 2017;43:109-16.

12 Barck-Holst P, Nilsonne Å, Åkerstedt T, et al. Reduced working hours and stress in the Swedish social services: A longitudinal study. International Social Work 2015.

13 Bildt C, Åkerstedt T, Falkenberg A, et al. Arbetstidsförkortning och hälsa. Försök med sex timmars arbetsdag inom offentlig sektor. Stockholm: Arbetslivsinstitutet, 2007.

14 Karasek R. Stress, productivity and the reconstruction of working life. New York: Healthy Work, 1990.

15 Statistics Sweden, living conditions, report 123; Swedish time-use survey 2010/2011. Örebro: SCB, 2012.

16 Anttila T, Nätti J, Väisänen M. The experiments of reduced working hours in Finland. Impact on work-family interaction and the importance of the sociocultural setting. Community Work Fam 2005:8:187-209.

17 Statistics Sweden, women and men in Sweden 2016. Örebro: Statistics Sweden, 2016.

18 Demerouti E, Bakker AB, Geurts SAE, et al. Current perspectives on job-stress recovery. Res Occup Stress Well Being 2009;7:85-123.

19 Sonnentag S. Work, recovery activities, and individual well-being: a diary study. J Occup Health Psychol 2001;6:196-210.

20 Eurostat, harmonised European time-use surveys - 2008 guidelines. Luxembourg: European Communities, 2008.

21 Sonnentag S, Bayer UV. Switching off mentally: predictors and consequences of psychological detachment from work during off-job time. J Occup Health Psychol 2005; 10:393-414.

22 Sonnentag S, Natter E. Flight attendants' daily recovery from work: Is there no place like home? Int J Stress Manag 2004;11:366-91.

23 Foundation focus, work-life balance: creating solutions for everyone. Dublin: European Foundation for the Improvement of Living and Working Conditions, 2016.

24 Morin CM, Rodrigue S, Ivers H. Role of stress, arousal, and coping skills in primary insomnia. Psychosom Med 2003:65:259-67. 